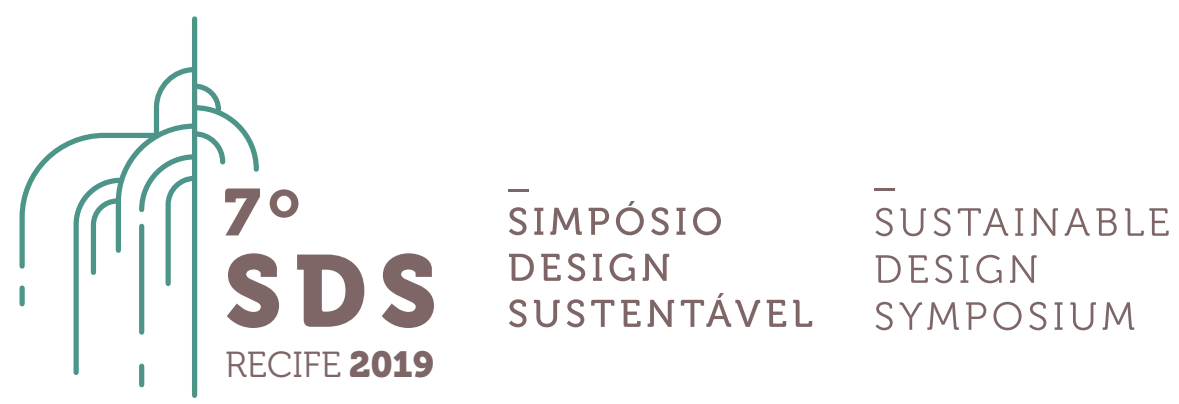

\title{
Da crise do projeto ao co-design na cidade: a pluriversidade como sustentabilidade?
}

\author{
Barbara Szaniecki ${ }^{1}$ e Mariana Costard ${ }^{2} \mathbf{a}$ \\ ${ }^{1}$ Universidade Estadual do Rio de Janeiro, Escola Superior de Desenho Industrial (ESDI/UERJ), \\ szanieckibarbara@gmail.com \\ ${ }^{2}$ Universidade Estadual do Rio de Janeiro, Escola Superior de Desenho Industrial (ESDI/UERJ), \\ marianacostard@gmail.com
}

\begin{abstract}
Resumo. Este artigo investiga as contribuições do design para a construção de cidades mais democráticas e sustentáveis a partir de uma abordagem interdisciplinar com a antropologia e uma prática colaborativa, reflexiva e crítica. Para tanto, partimos da crise de um projeto de cidade moderno ligado ao desenvolvimento do capitalismo, que gerou um espaço caracterizado pela concentração de pobreza e exclusão social, através da exploração insustentável do território e seus recursos. Apoiamos a necessidade de uma transformação da lógica hegemônica dualista e monocultural de ver mundo que permita "reativar" o pensamento através dos diferentes saberes e modos de vida. Trazemos essa discussão para o campo de teoria e prática do design na cidade, posicionando o designer como co-pesquisador e co-criador junto a projetos comunitários e cidadãos, abrindo espaço para as diferenças, o dissenso e a democracia a partir da relação com o outro e do uso de ferramentas visuais e dispositivos de conversa como métodos de um design político. Alinhada a uma "reorientação ontológica do design", entendemos que a sustentabilidade das cidades está necessariamente ligada à realização plena de sua pluriversidade.
\end{abstract}

Keywords. Codesign, design anthropology, cidades sustentáveis, pluriversidade.

\section{Introdução}

Cidades constituem a obra humana mais complexa. Nos últimos anos, apesar de todo o

${ }^{a}$ Apoio da Coordenação de Aperfeiçoamento de Pessoal de Nível Superior - Brasil (CAPES) - Código de Financiamento 001. 
conhecimento nelas concentrado, as cidades passaram a sofrer as consequências do êxodo rural, dos efeitos nefastos do desenvolvimento industrial e da perda da qualidade de vida. O campo do design vem buscando colaborar com essas questões. No que diz respeito à sustentabilidade, são muitas as contribuições em termos de produtos, de sistemas e de comunicação. Neste artigo, procuramos trazer uma perspectiva para a sustentabilidade das cidades a partir de uma postura colaborativa, transdisciplinar, reflexiva e crítica de design. A cidade não é o campo privilegiado de atuação do designer e, portanto, iniciamos o percurso com uma discussão acerca do projeto de cidade pelas vias do planejamento urbano que, como vamos observar, enfrenta uma crise. Ora, para tanto faz-se necessária, antes mesmo de projetar, uma transformação radical na forma de ver e pensar o mundo, uma descolonização do pensamento (Viveiros de Castro, apud Stengers, 2017), uma superação da lógica hegemônica dualista que permita "reativar" (Stengers, 2017) o pensamento através de diferentes saberes e modos de vida e, no campo do design, a sua reorientação ontológica (Escobar, 2017). Este artigo traz essas reflexões para o campo de teoria e prática do design na cidade. Posicionamos o designer como co-pesquisador e co-criador junto a projetos comunitários e cidadãos, abrindo espaço para as diferenças, o dissenso e a democracia a partir da relação com o outro e do uso de ferramentas visuais e dispositivos de conversa como métodos de um design político (DiSalvo).

Situada no Laboratório de Design e Antropologia (LaDA-Esdi), a abordagem aqui apresentada trabalha de forma interdisciplinar com a antropologia, procurando criar coletivamente cidades pluriversais enquanto sustentáveis.

\section{A crise do projeto de cidade}

Não é de hoje que o projeto moderno de cidade e o modelo de planejamento urbano funcionalista é criticado na medida em que tende a homogeneizar as práticas sociais e apresenta dificuldade em apreender "a urbanidade", ou seja, a vida urbana em sua complexidade. Este emaranhado produtivo, político e afetivo cotidiano requer um olhar mais atento aos detalhes e uma atitude cautelosa com os processos. É com essa postura que o design pode atuar e assim contribuir para a construção coletiva de um espaço urbano mais democrático.

Já em 1961, Jacobs criticava os fundamentos do planejamento e da reurbanização (Jacobs, 2000) baseados em princípios e objetivos modernos ortodoxos. Convencida que as cidades são um imenso laboratório de desenho e construção, sugere que especialistas do planejamento urbano observem os usos cotidianos que os cidadãos fazem dos espaços urbanos. Embora analise aspectos concretos como as quadras e os prédios em termos de qualidades estruturais e de concentração, seu foco é nas pessoas e, em particular, na diversidade humana que essas construções podem abrigar e ampliar. Considera que a mera aplicação de teorias prontas acabam por expropriar e até expulsar pessoas e comunidades, isto é, por saquear as cidades. Jacobs defende portanto a diversidade das práticas e a combinação de usos como meios capazes de resistir a esses processos e garantir a vitalidade urbana.

Também nessa época, Lefebvre (1968) considerava que a cidade assumia o papel de grande laboratório do homem para sua reflexão teórica e ação prática, sendo o processo de industrialização aquele que mais induziu à urbanização desenfreada e produtora de espaços cheios de dualidades e contradições. A cidade é "obra" dos cidadãos, uma produção contínua definida por suas condições históricas e que, portanto, muda junto com a composição da sociedade. Ora, por um lado a pretensão de apreensão da totalidade e síntese da cidade por parte de um urbanismo racionalista reduz os encontros e confrontos dos diferentes modos de vida que constituem o "urbano". Por outro, o neocapitalismo e sua lógica economicista tentam colocar ordem na confusão caótica da cidade, 
fazendo prevalecer o valor de troca sobre o valor de uso, sob uma estratégia de classe que expulsa as classes trabalhadoras dos centros de decisão e concentra cada vez mais poder e privilégios. Diante desse quadro, Lefebvre considera que uma ciência da cidade não é a soma dos conhecimentos fragmentados das ciências parcelares e ainda menos a sua subordinação a uma finalidade no seio de uma estratégia política unificada. O direito à cidade que ele defende é um direito à vida urbana em sua plenitude de encontros, usos e ritmos; deve ser meio e objetivo para uma revolução urbana cuja estratégia se opõe à dominação, devolvendo aos cidadãos segregados o lugar de sujeitos do espaçotempo que habitam.

Recentemente, Harvey (2014) retomou alguns argumentos de Lefebvre para apontar que a ideia de direito à cidade surge das ruas como um "grito de socorro" de pessoas oprimidas pela acumulação de excedentes de produção características do desenvolvimento do capitalismo com consequências muito específicas no espaço urbano. A "produção capitalista do espaço" (Harvey, 2014) priorizou os interesses econômicos às necessidades humanas e, por meio de processos de desapropriação, privatização e gentrificação sem participação cidadã, gerou um espaço caracterizado por concentração de pobreza e exclusão social, além de imensa degradação ambiental. Sem desdenhar o papel do Estado, Harvey afirma que reivindicar o direito à cidade é reivindicar algum tipo de poder coletivo sobre os processos de urbanização, sobre o modo como nossas cidades são feitas e refeitas. Nesse sentido, reconhece as multiplicidades de práticas urbanas como alternativas possíveis (heterotopia de Lefebvre) mas também, a partir de episódios recentes como o Occupy Wall Street nos Estados Unidos e os conflitos pré-olímpicos em Londres, ambos em 2011, aponta o potencial revolucionário dos movimentos sociais em suas lutas nas cidades.

No Brasil, o projeto de cidade também ocasionou críticas. O Planejamento Estratégico, por exemplo, vem sendo criticado por importar um modelo empresarial, guiado por uma competitividade urbana dos mercados financeiros internacionais. Em resposta ao aumento da população e às transformações das cidades, operações urbanas foram implementadas de forma homogeneizante, sem considerar as especificidades locais. Projetos de revitalização e requalificação recentes estão associados a um tipo de planejamento que acaba por intensificar as desigualdades sociais e a produção de um território excludente. Entre seus modus operandi, estão as parcerias público-privadas que, com o objetivo de recuperar espaços urbanos tido como degradados transformando-os em lugares de consumo, atraem classes com maior poder aquisitivo e excluem a população de baixa renda (Magnani, 2002).

De acordo com Carlos Vainer (2000), esse tipo de projeto é apropriado por interesses empresariais globalizados e trata a cidade como "mercadoria", "empresa" e "pátria". Um de seus instrumentos é a institucionalização da parceria público privada (PPP) que, embora seja apresentada como forma de participação nas políticas públicas, constitui a seu ver um processo autoritário de "democracia direta da burguesia" (Vainer, 2000). Da crítica ao urbanismo modernista baseado num modelo racional e funcional de ordenamento, o modelo estratégico empresaria a cidade, subordinando-a às lógicas do mercado baseadas em eficácia, produtividade e competitividade. Em suma, mais uma vez, vemos aqui o valor de uso sendo subordinado ao valor de troca como já apontava Lefebvre. Vainer ressalta ainda que esse modelo reduz as questões da cidade a problemas de natureza gerencial enquanto nega o espaço político e o exercício da cidadania na medida em que seus processos visam a eliminação dos conflitos por meio da produção de consensos, isto é, uma despolitização planejada da cidade.

Esse panorama crítico apresenta concepções e práticas de "projeto de cidade" que, além de 
homogeneizantes e excludentes, restringem o espaço político e o exercício da cidadania. Estão, ainda, associadas a uma postura de exploração descontrolada e predatória do território e seus recursos ambientais, acompanhadas da manutenção de um estilo de vida consumista e individualista que apenas reforça essa degradação. Contudo, para além da análise critica do papel do capital global e do Estado nacional nesses processos, encontramos indicações de que, nas práticas cotidianas e nas lutas urbanas, existem possibilidades de reivindicação de uma democracia das diferenças por meio da criação coletiva da cidade. É neste urbano que procuramos abrir brechas para uma atuação por meio do design, na tentativa de transformar as cidades contemporâneas em mais acolhedoras do dissenso e, nesse sentido, mais pluriversais.

\section{0 problema do desenvolvimento e as perspectivas do sul global}

Para além da critica ao projeto de cidade e com o intuito de melhor qualificar o design que propomos, nos interessa refletir sobre a concepção de modernidade que direcionou a criação de mundos e modos de vida. Inspiradas por uma perspectiva do sul global, desejamos contribuir com uma experiência de conhecimento situado, porém sem incentivar uma polarização entre Norte e Sul, e sim a constituição de ambos numa relação onde não caiba subalternidade. Um "sul" que não seja "sub".

Um dos maiores condutores dessa hierarquização dos seres e das nações - que continuamente reduzem o Sul ao "sub" - é a noção de desenvolvimento. Segundo Acosta (2016), o "discurso sobre o 'desenvolvimento' estabeleceu - e consolidou - uma estrutura de dominação dicotômica: desenvolvido-subdesenvolvido, pobre-rico, avançado-atrasado, civilizado-selvagem, centro-periferia". E complementa: "Inventou-se o Terceiro Mundo e seus membros foram instrumentalizados qual peões no xadrez da geopolítica internacional. Uns e outros, direitas e esquerdas, estabelecendo diversas especificidades e diferenças, assumiram o desafio de alcançar o desenvolvimento." (Acosta, 2016, p. 47).

Nesse mesmo sentido, Arturo Escobar (2017) afirma uma crise da lógica dualista necessária à manutenção e expansão de formas hegemônicas de conhecimento. Ele reconhece a transição em andamento e a necessidade de se orientar esse processo para uma lógica relacional, conectada com as transformações da vida, e de rejeitar o racionalismo que produz um mundo de "pensamento único" em prol de uma ontologia em que os humanos o constituem, não como objetos e sim como sujeitos autônomos. Segundo o autor, debates sobre decrescimento proliferam nos países do Norte, em geral associado aos termos comunalização, commons ou comuns, enquanto "debates sobre o pósdesenvolvimentismo e as alternativas ao desenvolvimentismo ganharam força na América Latina da última década em conexão com a onda de regimes progressistas que se iniciaram em finais de 1990" (Escobar, 2017, p. 168).

Algumas dessas alternativas ganham no contexto latinoamericano o nome de Buen Vivir. Remontando às ontologias indígenas, elas valorizam os conceitos de dignidade, justiça social e biocentrismo em detrimento de objetivos econômicos guiados por um suposto progresso. Nesse sentido, se apresentam como projeto político-cultural que visam a realização de um bem-estar comum por meio da construção coletiva de novos modos de vida (Escobar, 2016), rumo à comunhão entre humanidade e natureza e à construção de sociedades solidárias e sustentáveis. No entanto, não devem ser tomadas como modelos a seguir, o que cristalizaria a concepção de um Bem Viver em sua pluralidade. 
Mesmo as teorias críticas dos anos 60 - Acosta menciona o estruturalismo e a teoria da dependência - não chegaram a desmontar a ideia convencional de desenvolvimento entendido como progresso linear que se expressa em taxas de crescimento econômico. E assim chegamos por caminhos tortuosos, após um final de século 20 sob governos autoritários, a um início de século 21 promissor com a chegada de governos progressistas na América Latina. Essa abertura se deu pela pressão dos movimentos sociais e pela própria incorporação de outros modos de pensar e de fazer que procuram tensionar os paradigmas desenvolvimentistas: o Bem Viver contribui com suas práticas para essa caminhada.

Inspirado por essa noção, Escobar (2017) se interessa por abordagens do design que busquem contribuir para as transições culturais e ecológicas necessárias ao enfrentamento das crises do clima, dos alimentos, da energia, da pobreza e dos significados. Ele reforça a importância da consciência histórica de que o design moderno surgiu associado às ideias de desenvolvimento e progresso, assim como a um entendimento ocidental de mundo que inferioriza e torna invisível a diferença e os conhecimentos subalternos, a partir de parâmetros de produtividade e eficiência da visão monocultural da economia de mercado. Para se contrapor a essa perspectiva, propõe um "design ontológico", situado entre entendimento e criação e comprometido com a produção do ser humano e do mundo, por meio da criação de ferramentas e tecnologias que abram outras possibilidades de ser e viver. Dessa forma, o design ontológico tem necessariamente um caráter crítico e carrega um potencial radical de inovação, na medida em que envolve repensar como está organizada a sociedade, seus valores e modelos, assim como pretende superar as formas convencionais de produzir que estão destruindo o planeta.

Para além dessa perspectiva crítica, Escobar propõe seu direcionamento para um design relacional e engajado com as lutas sociais de comunidades em defesa de sua autonomia de seus mundos-vida, configurando o que ele chama de design para o pluriverso. Esse design que também é autônomo tem como objetivo a realização do "comunal", entendido como autocriação contínua da própria comunidade por meio de ferramentas que contribuam para reimaginar e reconstruir mundos locais. Ele parte do pressuposto que toda comunidade pratica o desenho de si mesma e de seu próprio saber e, portanto, os designers se tornam co-investigadores num sistema de investigação próprio, já existente. Nele, acolhem tanto a ancestralidade como a construção de futuros comuns, privilegiando formas de organização não patriarcais, não liberais, não centradas no Estado e não capitalistas. Nesse sentido, essa mudança de perspectiva do design que se abre para outros modos de vida, pretende afetar mudanças profundas de comportamento e estilo de vida que hoje agravam as condições ambientais do planeta e das cidades.

\section{Design e antropologia como modo de fazer e habitar a cidade}

Situadas no Laboratório de Design e Antropologia (LaDA/Esdi), mantemos uma atividade acadêmica interdisciplinar, subsidiada por reflexões teóricas e experimentos práticos que buscam compor um modo de fazer que possa contribuir para a construção de cidades pluriversais enquanto cidades sustentáveis. A aproximação com a antropologia tem um caráter reflexivo e crítico sobre como nos posicionamos no mundo e nas relações com os outros. O design anthropology se apresenta como um campo híbrido de produção de conhecimento contextualizado e situado, com práticas de pesquisa experimentais e posicionamento propositivo, na busca de um diálogo prático entre profissionais e cidadãos para a cocriação de alternativas possíveis para o presente e o futuro; é um modo de estar no mundo compromissado com a observação mas também engajado com a sua 
transformação (Anastassakis, 2013; Gunn et al., 2013). Sua metodologia pode ser assumida como potencialmente descolonizada (Tunstall, 2013), para um engajamento profundo com questões sociais e comunidades, contribuindo para desmistificar ideologias hegemônicas e co-produzir formas de conhecimento libertadoras.

O posicionamento proposto por Ingold para uma antropologia por meio do design tem sido adotado pelo campo denominado design anthropology como modo de estar em campo atuando em correspondência às dinâmicas de crescimento e transformação das pessoas envolvidas em um processo de movimento e ação reflexiva (Ingold, 2013; Gatt e Ingold, 2013). O autor cultiva uma "educação da atenção" (Ingold, 2016) na prática antropológica, em contraposição a um relato etnográfico distanciado e desligado do mundo que se observa. Entende que não é possível separar esse conhecimento almejado do próprio estar no mundo, portanto de uma observação participante e engajada, "em correspondência". Essa postura antropológica de lidar com o outro permite cultivar uma reflexão permanente sobre o nosso papel na construção do mundo que criamos (e mesmo nos processos de design), o que Stengers chama de "atenção imanente" (Stengers, 2017) - esse desafio crítico de apego a uma verdade.

Ao "reativar o animismo" (Stengers, 2017), Stengers pretende confrontar uma Ciência voltada à conquista do mundo, que serviu para justificar a colonização e a categorização que ainda persiste hoje, através de um pensamento racional e dualista com poder de validar os conhecimentos que podem existir. A Ciência "maior" (diferenciada pela autora com o uso da letra maiúscula, em oposição às aventuras das realizações científicas) categoriza o animismo como sobrenatural por não saber explicar, determinando sua não existência enquanto verdade. Stengers defende uma ciência aventureira, baseada em experimentos que questionem as próprias perguntas e possibilitem a criação de novas perguntas, colocando em risco seu modo hegemônico de pensamento; propõe uma prática situada que convide à participação, buscando criar pontes e tecer relações entre diferentes modos heterogêneos de vida, sem privilégios e passíveis de outras conexões.

É uma proposta para a prática científica mas também inspiradora para o design, especialmente na relação com o outro e com o mundo (e as cidades) que está procurando construir. Analisando o jogo antropológico na relação social entre o observador e o 'nativo', Viveiros de Castro (2002) aponta que o antropólogo deve recusar a vantagem estratégica de discurso numa relação unilateral e reivindicar uma igualdade de direito entre os sujeitos. Essa postura vai além de assumir o outro como sujeito ao invés de objeto, para deixar-se alterar a partir do outro, evitando sua circunscrição em um conhecimento antecipado, que acaba por limitar seus mundos possíveis. Multiplicar e experimentar a variação das relações sociais, deixar o mundo do outro afetar o nosso: é essa postura que tentamos transpor para a prática de design, especialmente no fazer coletivo em contextos urbanos.

Além dessa postura em relação ao outro, o design conjugado com a antropologia também pode nos ajudar a pensar um projeto de cidade mais engajado com suas práticas sociais e com dimensões mais subjetivas da vida cotidiana, respeitando a "produção do espaço" (Lefebvre, 2000) como "obra", pelos próprios cidadãos. Para isso, evocamos a diferenciação que Lefebvre (Lefebvre, 1968) faz entre habitar e habitat para pensar a forma como nos relacionamos com o espaço e o mundo em que vivemos. Ele diz que "habitar" era participar de uma vida social, de uma comunidade ou cidade, como qualidade da vida urbana, que permitia que os cidadãos se realizassem na preservação e uso do espaço. O conceito de "habitat" surge como direito à moradia "levado à sua forma pura pela burocracia estatal" (Lefebvre, 1968, p. 26), com a racionalidade de funções e tempos, 
que exclui o "habitar". Essa concepção se relaciona com a ideia de Ingold (2015) de "habitar o mundo" através do caminho que estabelecemos historicamente com nossas vidas, juntando-se ao seu processo de formação. Para ele, "a habitação não é meramente a ocupação de estruturas já construídas, não está para a construção como o consumo está para a produção" (Ingold, 2015, p. 34). O mundo está vivo e habitá-lo significa imergir nas correntes da vida, o que "concerne à maneira como os habitantes, isolados e em conjunto, produzem as suas próprias vidas, e como a vida, prossegue" (Ingold, 2015, p. 34).

Desejamos habitar nossas cidades. Nesse sentido, buscamos aqui construir um pensamento junto com uma prática de design na/com a cidade que exercite essa postura antropológica de habitar o mundo e uma atenção imanente na relação com o outro. A partir do engajamento dialógico com lugares e pessoas, pretendemos produzir processos colaborativos para a invenção e reconstrução de cidades mais coerentes com os desejos e necessidades de seus habitantes. É nesse processo que pensamos conjugar pluriversidade com sustentabilidade, no sentido de reconhecer que a sustentabilidade só é possível a partir de teorias e práticas que extrapolam a pretensa universalidade do design e da cidade em suas vertentes modernas.

\section{Co-design na cidade: abordagem teórica e experimentos práticos}

Escobar aponta uma conjuntura favorável para a construção de uma agenda de design definido por ele como autônomo e pluriversal desde o espaço teórico-político das atuais lutas sociais, em particular dos movimentos e comunidades indígenas, afrodescendentes e campesinas. Apesar da importância das lutas no campo, optamos por construir nossa agenda de design no espaço urbano, considerando que nosso país se configura hoje com mais de $85 \%$ de sua população vivendo em áreas urbanas. Na realidade, consideramos que urbano e rural são indissociáveis e as lutas sociais nos mostram isso. O que essas concepções podem nos ensinar para a atuação em contextos urbanos complexos e em prol da sustentabilidade?

Nossa atuação no LaDA tem experimentado modos de fazer (co)design na cidade, buscando construir coletivamente esse espaço urbano em que vivemos e incorporando as pessoas no processo como criadoras de seus próprios mundos, com postura reflexiva e relação de "atenção imanente" com o outro. Para isso, temos desenvolvido ferramentas e métodos enquanto táticas que tensionam as estratégias dominantes de construção das cidades tais como o planejamento urbano abordado anteriormente. Dessa forma, assumimos um papel na "construção de públicos" (DiSalvo, 2009) em torno de assuntos de interesse, na reunião de indivíduos e grupos diferentes para resolver problemas comuns, a partir de perspectivas divergentes e distantes de um consenso compartilhado. Buscamos devolver à cidade seu lugar político e de exercício da cidadania, na prática de um "design político" que tenta contribuir para a ampliação de uma democracia agonística, não hegemônica e consensual, mas baseada no conflito e disputa entre ideais, valores e crenças concorrentes. O "design antagonista" (adversarial design) encoraja a contestação e o dissenso através de ambientes projetados para apoiar o reconhecimento de questões, discursos e práticas, revelar e confrontar relações de poder e possibilitar reivindicações e argumentos contestatórios (DiSalvo, 2015).

O potencial democrático da participação em processos de design pode ser explorado através de métodos e ferramentas de visualização, imaginação, experimentação e reflexão contínua, preparando condições férteis para uma discussão ampla e democrática sobre questões controversas (Binder et al., 2015). Denominadas "coisas de design" (design Things), essas atividades representam 
"assuntos de interesse" e meios de gerar reuniões sócio-materiais para articular condições sociopolíticas (Latour, 2005): procuram criar um lugar comum para negociar conflitos, discutir ideias e interesses diversos; traduzem interesses em linguagem compartilhada para mediar questões e comunicar visões; assumem um papel de mediação de uma investigação com objetivos relacionais abertos a interpretações (Bjögvinsson, 2012; Koskinen, 2011; Manzini, 2015).

No LaDA, temos explorado esse modo de fazer através dos "dispositivos de conversação" (Anastassakis e Szaniecki, 2016) enquanto experimentos de pesquisa e diálogo no cenário urbano. Na teoria, a proposta articula o conceito de dispositivo desenvolvido por Michel Foucault como um conjunto de relações de força que formam uma rede de conexões entre possibilidades e suas transformações com aquele de "conversação" inspirado em Mikhail Bakhtin tal como uma construção compartilhada de discursos possíveis que difere da opinião formada por meio da comunicação. Na prática, desenvolvemos artefatos de visualização para construir processos abertos de engajamento e imaginação coletiva sobre visões possíveis, formando uma estrutura horizontal e transversal entre agentes heterogêneos com diferentes conhecimentos e práticas, em abordagem transdisciplinar.

A pesquisa de doutorado aqui relacionada tem investigado as temáticas expostas neste artigo através de experimentos práticos que envolvem ações focadas nas possíveis melhorias de um bairro. Alinhada com a proposta de um design autônomo, elas questionam os parâmetros de desenvolvimento e revitalização urbana a partir de uma prática local. "Rio Comprido em Nós" é um projeto iniciado durante o mestrado que investiga as questões de interesse do bairro do Rio Comprido (Rio de Janeiro) através da atuação engajada com a comunidade local utilizando ferramentas mediadoras para provocar o diálogo, a reflexão crítica e a imaginação coletiva sobre as questões locais e alternativas voltadas para o futuro. Como desdobramento, participou de ações do coletivo Baixo Rio que atuou por um longo período no bairro do Rio Comprido com propostas para sua revitalização. Buscou-se acompanhar suas interferências "de fora" e contribuir para um diálogo mais aberto com as pessoas, estimulando uma reflexão sobre como aumentar a participação local em projetos que visam uma escala mais sistêmica e estratégica.

Outro projeto que resultou desse envolvimento com o Rio Comprido foi realizado em colaboração com o Colégio de Aplicação da Universidade do Estado do Rio de Janeiro (CAp-Uerj), que tem como componente curricular no terceiro ano do ensino fundamental o estudo do bairro onde a escola fica localizada. Convidada para apresentar a pesquisa para as crianças, a parceria pontual acabou se desdobrando em um ano de atividades de diferentes naturezas, como: cartografias coletivas, jogos, ferramentas de visualização e imaginação, maquetes, expedição, exposições. Formou-se uma investigação colaborativa e transdisciplinar sobre o bairro do Rio Comprido, envolvendo professores e pesquisadores de diferentes áreas do conhecimento, alunos e alunas, além de moradores locais. Nesse processo, o design atuou em correspondência, atravessando diversos momentos, construindo pontes e articulando ações conjuntas entre os diferentes campos e saberes. Além da diversidade presente em todo o processo, o envolvimento das crianças no pensamento e projeto de cidade contribui para a oposição às práticas institucionalizadas e hegemônicas discutidas neste artigo, já que possuem visões de mundo consideradas dominadas na opressora disputa pelo conhecimento - assim como os povos tradicionais e outras minorias (Ingold, 2017). Dessa forma, elas passam a se perceber como produtores do mundo e este como algo passível de transformação. 

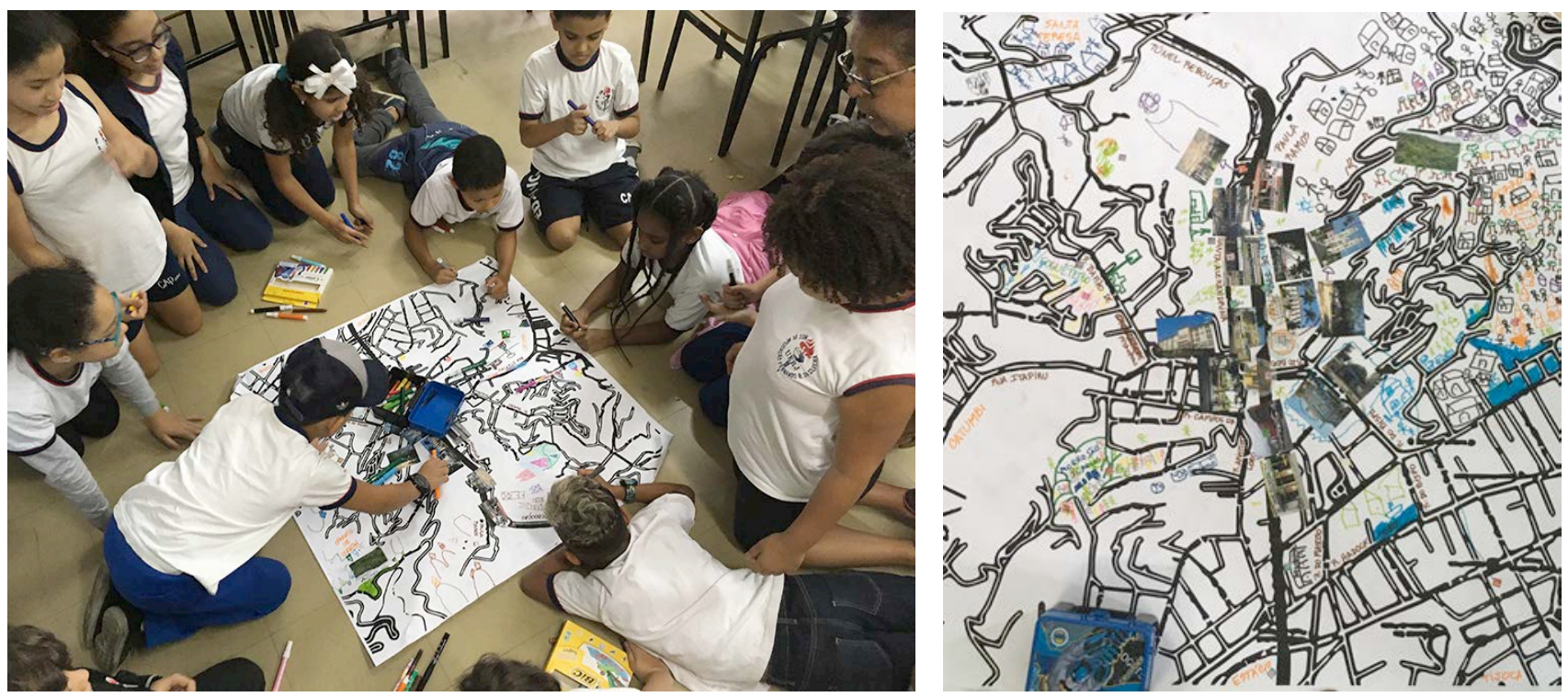

Rio Comprido em Nós + CAp-Uerj: cartografia coletiva.
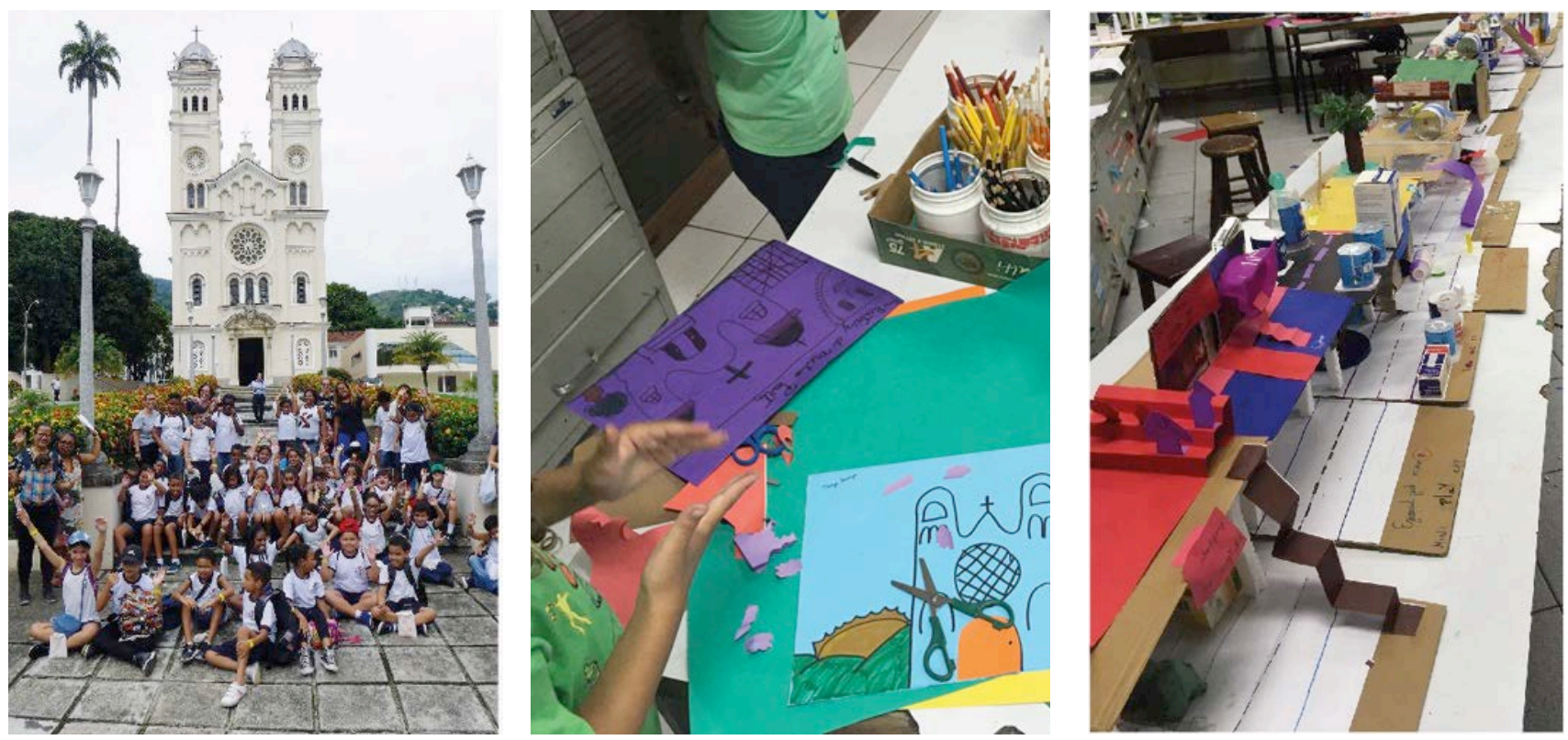

Rio Comprido em Nós + CAp-Uerj: expedição pelo bairro, cartões postais, maquetes. 


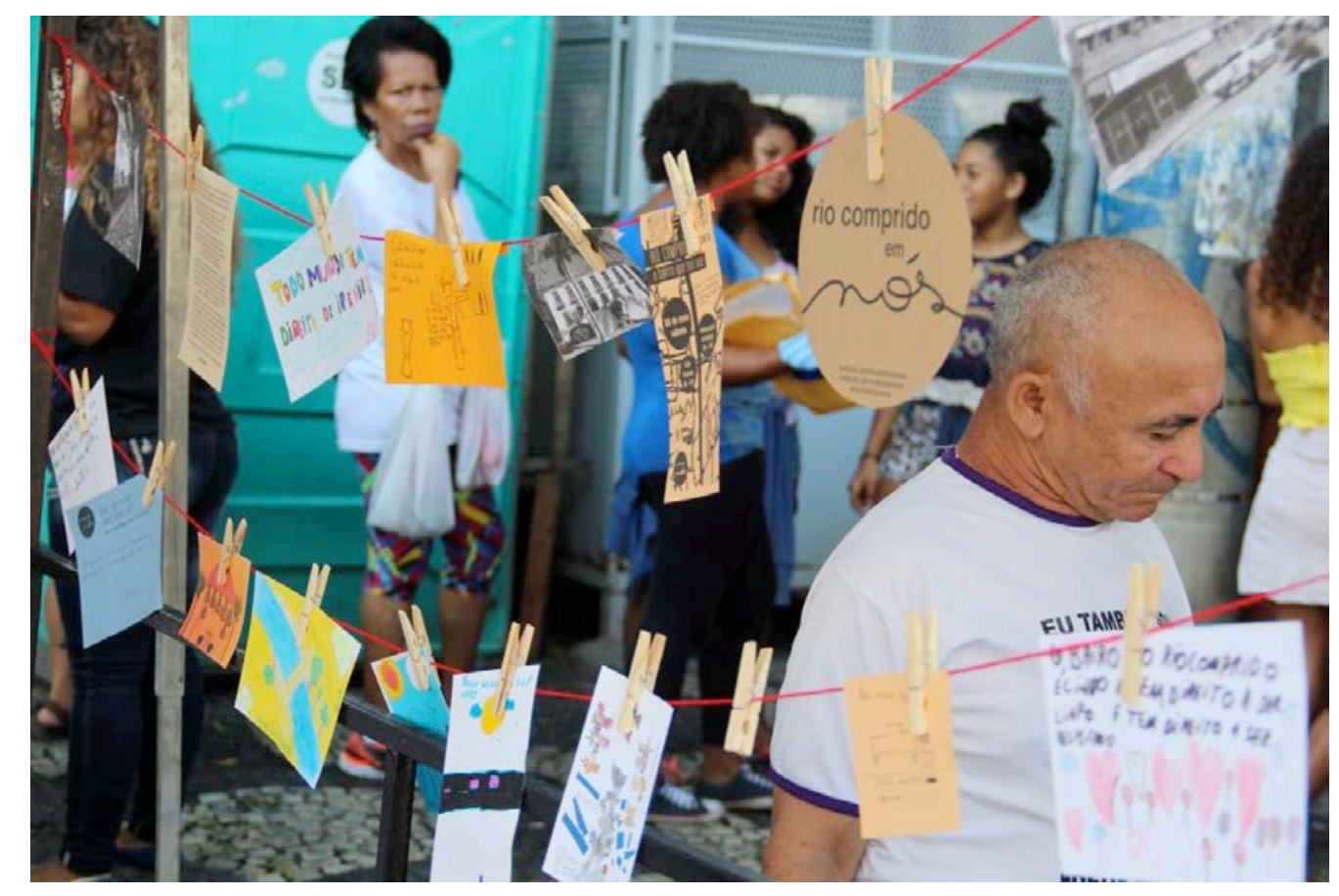

Rio Comprido em Nós + CAp-Uerj: exposição na praça, conversas com moradores.

Além dessa pesquisa focada no bairro do Rio Comprido, atividades mais difusas têm contribuído para pensar as possibilidades de atuação do design na cidade, a partir dessa abordagem colaborativa, reflexiva e política. Como atividade de pesquisa coletiva, o curso teórico-prático "MapaPraça-Máquina: experiência de design colaborativo no espaço público", concebido de forma co-criada entre a coordenadora Barbara Szaniecki e os pós-graduandos da Esdi Talita Tibola, Liana Ventura e Philippe Leon Anastassakis entre outros, trouxe experimentações inspiradoras e a reunião de ferramentas para a atuação colaborativa de design nos espaços urbanos. Realizado na Praça Tiradentes como atividade de extensão da Esdi-Uerj em parceria com o Centro Municipal de Arte Hélio Oiticica (CMAHO), o curso partiu da articulação desses três elementos - mapa, praça e máquina - para evocar e incitar o encontro entre heterogeneidades: o mapa como mote de conversação e captura de informação, a praça como o potencial local desses processos e a máquina, já presente ou ainda por ser construída, como aquela que vem atualizar essa potência. Nessa mistura, buscamos investigar o que faz funcionar os encontros e o que produz engajamento, entendendo o design como uma importante ferramenta na criação de cidades com diversidade e, sobretudo, pluriversidade. 

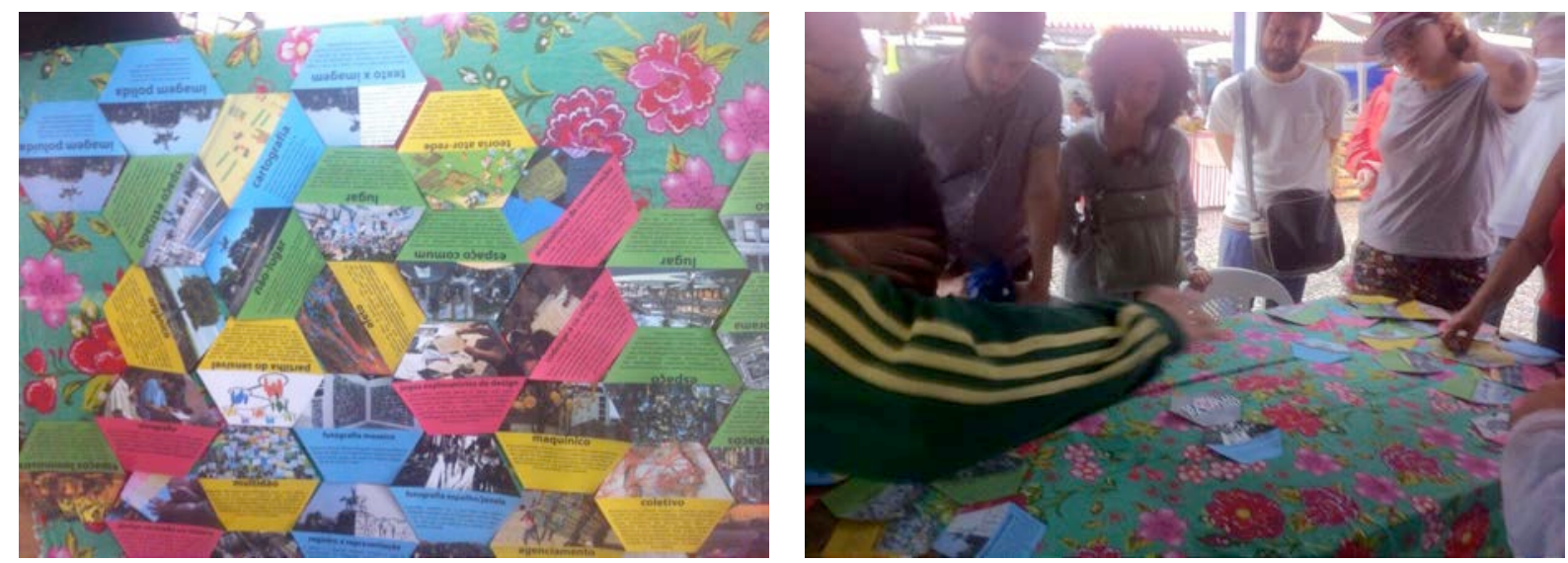

Dispositivos de conversação: jogo dos verbetes
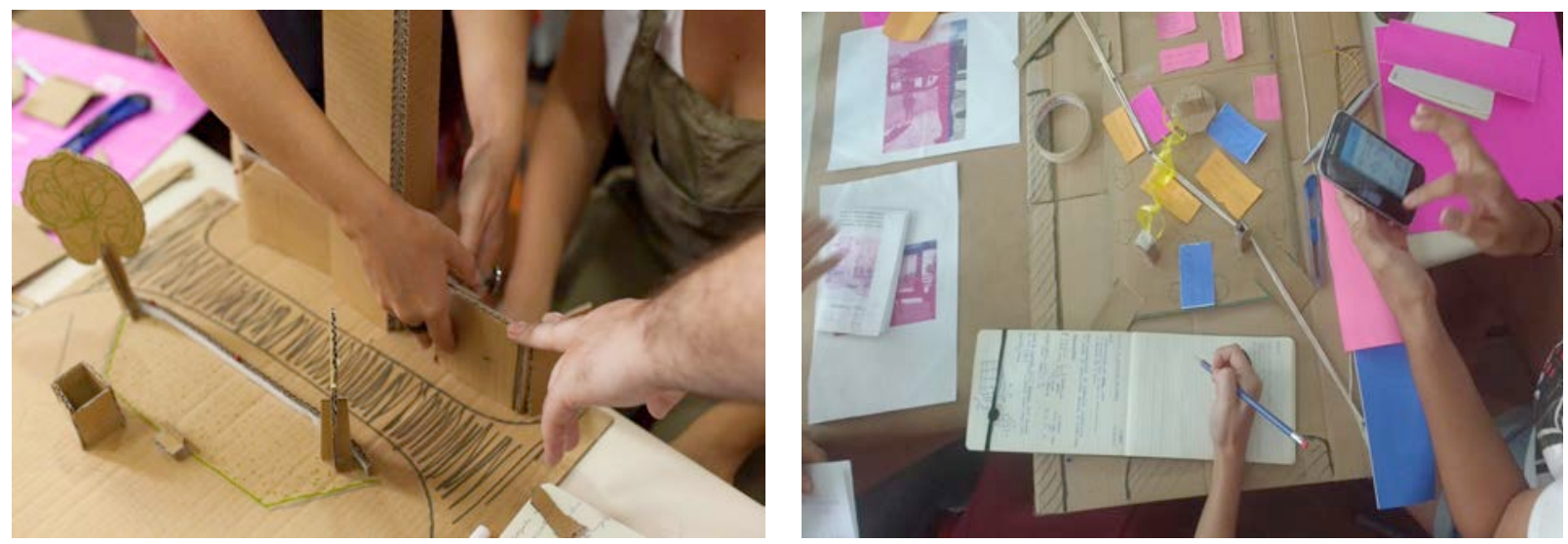

Dispositivos de conversação: protótipos e provótipos
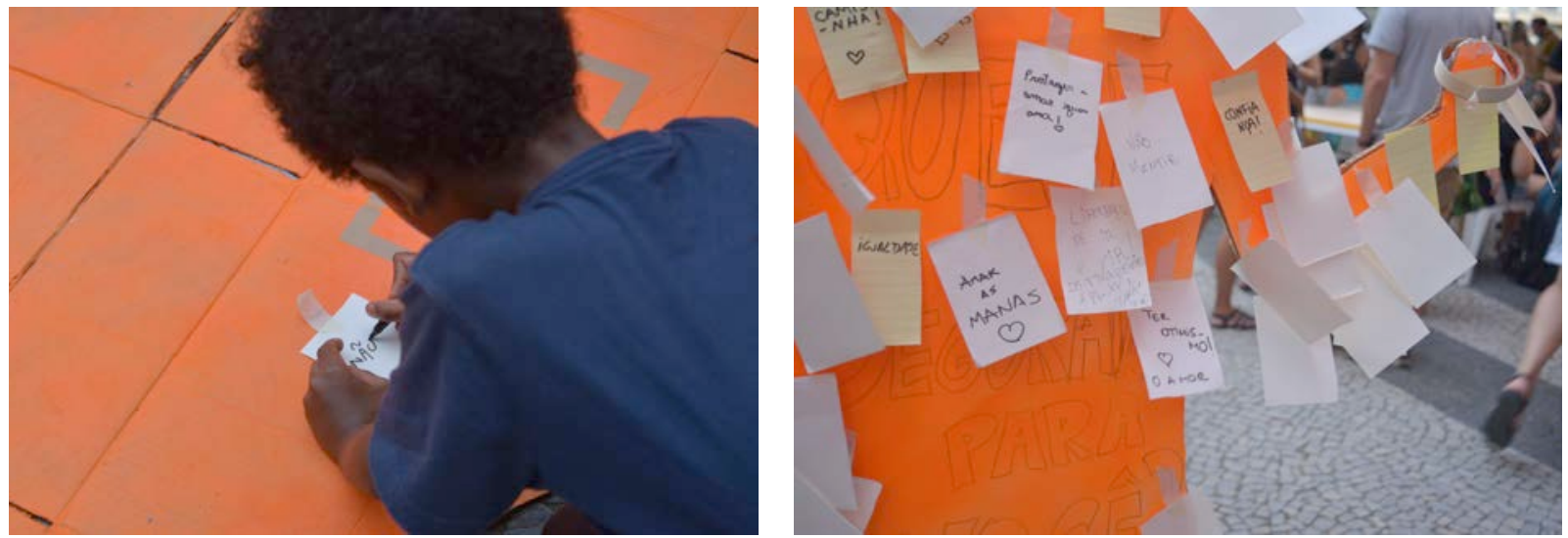

Dispositivos de conversação: jogos na praça sobre a questão da segurança durante o evento Tiradentes Cultural. 


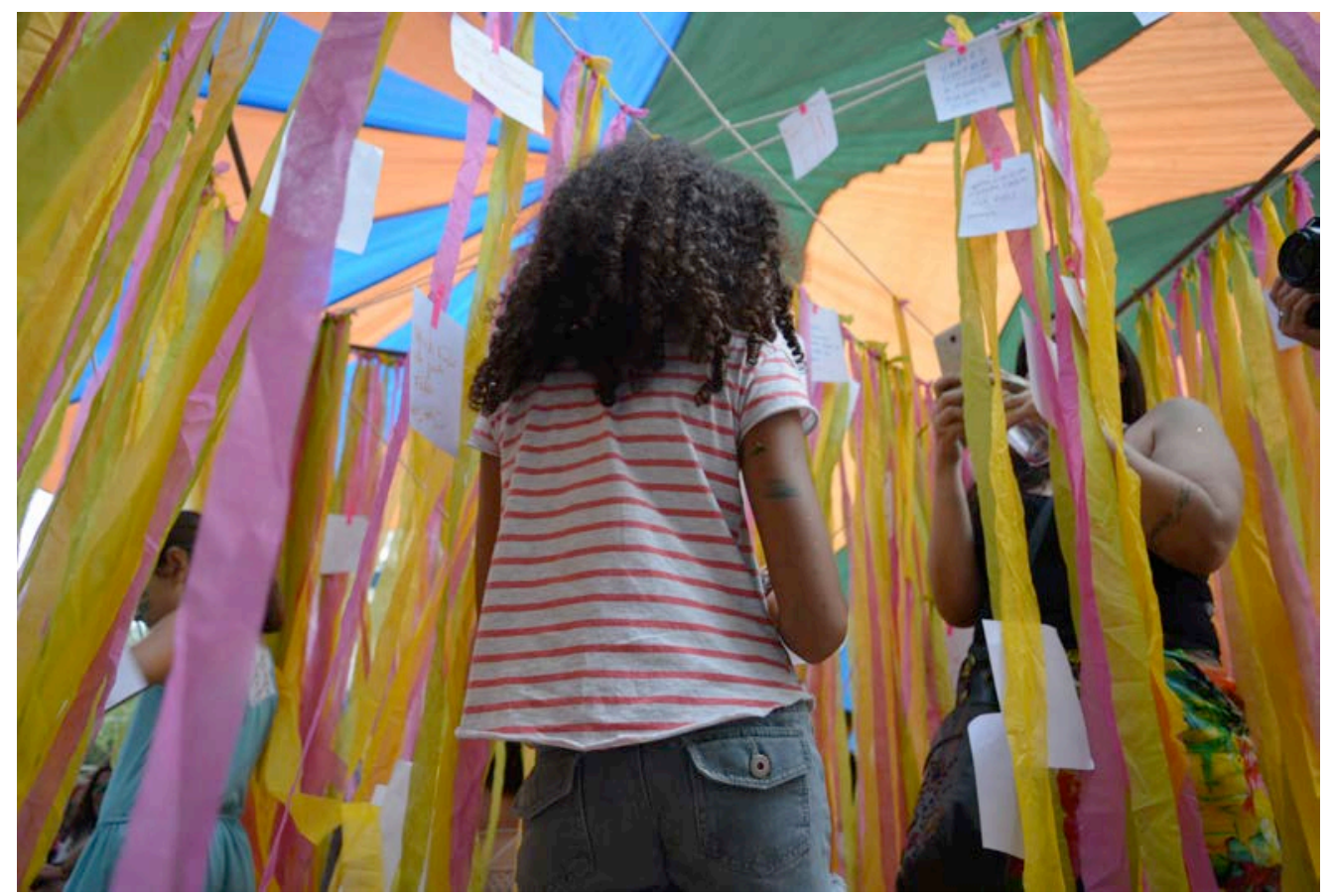

Dispositivos de conversação: jogos na praça durante o evento Tiradentes Cultural. Coleta e análise das percepções e desejos dos frequentadores da praça

Outros experimentos de design na cidade têm sido desenvolvidos nas aulas de graduação da Esdi-Uerj. Tomando o cenário urbano como temática para as aulas de projeto, os alunos têm explorado ferramentas de design para propor reflexões, intervenções e/ou soluções para as questões observadas, sempre de modo engajado com o campo e as pessoas. A disciplina Desenvolvimento de Projeto em Programação Visual, realizada em 2018 com uma turma de terceiro ano pela professora Barbara Szaniecki (em parceria com a professora Talita Tibola e Mariana Costard como estagiária), teve a cidade como pano de fundo e o objetivo de promover a cidadania. O percurso se dividiu em dois módulos, sendo o primeiro de análise do espaço urbano e político, em que os alunos foram expostos a ferramentas diversas de engajamento e apreensão de usos dos lugares que escolheram para realizar suas pesquisas e projetos. Algumas referências teóricas embasaram as idas a campo, assim como a sugestão de possíveis exercícios: observação, anotações, desenhos, fotografia, contagem, mapeio, rastreio, coletas, entrevistas, cartografias... O segundo módulo da disciplina foi de desenvolvimento do projeto - um "objeto gráfico editorial" (revista, zine ou outros) que reunisse a pesquisa realizada e articulasse sua história oficial com as muitas estórias possíveis, recolhidas a partir da escuta e percepção visual, na perspectiva de um design para/na cidade.

A disciplina Projeto em Design de Serviços desenvolvida no primeiro semestre de 2019 com uma turma do segundo ano, teve como professoras Talita Tibola, Mariana Costard e Liana Ventura, sob supervisão da professora Barbara Szaniecki. Esse modo de fazer coletivo nos acompanha em todo o processo, desde o planejamento das aulas às discussões e reflexões de cada etapa desenvolvida com a turma. Neste caso, partimos do bairro da Glória para pensar a cidade por meio do design, com parceria da Casa de Estudos Urbanos. Essa abordagem do design de serviços abrange, para além da lógica mercadológica, uma visão política e práticas de cidadania através do desenho de ações entre o território e a comunidade, estimulando uma atuação reflexiva e crítica sobre aquilo que criamos enquanto designers. Assim como na outra disciplina, trabalhamos em dois módulos, sendo o primeiro de maior contato com o campo e as comunidades envolvidas, através de ferramentas e métodos de 
design colaborativo, como os dispositivos de conversa. Através do engajamento dialógico com pessoas e lugares reais, os alunos foram orientados a perceber e construir suas próprias questões sobre o espaço urbano, que funcionaram como disparador de projetos de coisas intangíveis, como sistemas, serviços e ações, realizados no segundo módulo.

\section{Considerações finais}

Reconhecemos a importância da cidade como a obra humana mais complexa, como laboratório com diversidade de práticas e combinações de usos, mas com muitos problemas gerados por sua produção histórica ligada ao desenvolvimento do capitalismo, como a exploração insustentável do território e seus recursos, e um espaço caracterizado por concentração de pobreza e exclusão social. Partimos da reflexão sobre esse modelo civilizatório da modernidade capitalista ocidental que direciona a criação de mundos e modos de vida e da crise do projeto de cidade atrelado a um planejamento urbano que tende a homogeneizar a cidade e sua práticas sociais em nome do desenvolvimento e do progresso, com a manutenção de um estilo de vida consumista e individualista que agrava indefinidamente as questões ambientais.

Nesse contexto, procuramos construir pensamentos e práticas do design no sentido proposto por Escobar de um design relacional e engajado com as lutas sociais de comunidades em defesa de sua autonomia, seus territórios e mundos-vida. A partir da prática interdisciplinar com a antropologia, buscamos um modo de habitar e (co) criar cidades sustentáveis através da pluriversidade, o que requer uma postura reflexiva e crítica, com atenção imanente ao nosso papel na relação com o outro. O engajamento dialógico explorado pelo design anthropology permite um conhecimento aprofundado do contexto em que se envolve, da mesma forma que um posicionamento propositivo para a cocriação de alternativas para o presente e o futuro, se permitindo "reativar" por outros modos de vida.

Atuamos pela via de um design político com táticas que tensionam as estratégias dominantes de construção dos espaços urbanos, buscando devolver à cidade seu lugar político e de exercício da cidadania. Para isso, utilizamos ferramentas e métodos que exploram o potencial democrático da participação, reunindo pessoas e grupos em torno de assuntos de interesse para resolver problemas comuns, a partir de perspectivas divergentes e não consensuais. Dessa forma, construímos um modo de fazer (co) design na/com a cidade, reivindicando um poder coletivo de invenção e reconstrução mais alinhados com os desejos e necessidades dos habitantes, em sua pluriversidade. É nesse processo que entendemos que a sustentabilidade só é possível a partir de teorias e práticas que extrapolem a pretensa universalidade do design e da cidade em suas vertentes modernas.

\section{Referências}

ACOSTA, Alberto. 0 bem Viver - Uma oportunidade para imaginar outros mundos. São Paulo: Elefante, 2016.

ANASTASSAKIS, Zoy. Laboratório de Design e Antropologia: preâmbulos teóricos e práticos. In: Arcos Design. Rio de Janeiro: PPD ESDI UERJ. Volume 7 Número 1. pp. 178-193. Junho, 2013.

ANASTASSAKIS, Zoy; SZANIECKI, Barbara. Conversation Dispositifs: Towards a Transdisciplinary Design Anthropological Approach in Design Anthropological Futures edited by Rachel Charlotte 
Smith, Kasper Tang Vangkilde, Ton Otto, Joachim Halse, and Thomas Binder. New York, London: Bloomsbury, 2016.

BINDER, Thomas, et al. Design Things. The MIT Press, 2011.

BINDER, Thomas, et al. Democratic design experiments: between parliament and laboratory. CoDesign 11.3-4: 152-165, 2015.

BJÖGVINSSON, Erling; EHN, Pelle; HILLGREN, Per-Anders. Design things and design thinking: Contemporary participatory design challenges. Design Issues 28.3: 101-116, 2012.

DISALVO, Carl. Design and the Construction of Publics. Design issues 25.1 : 48-63, 2009.

DISALVO, Carl. Design, democracy and agonistic pluralism. Proceedings of the design research society conference. 2010.

ESCOBAR, Arturo. Autonomia y diseño - la realización Del comunal. Buenos Aires: Tinta Limon, 2017.

EHN, Pelle; Ehn, P., Nilsson, E. M., Topgaard. Making futures: marginal notes on innovation, design, and democracy. MIT Press, 2014.

GATT, Caroline; INGOLD, Tim. From description to Correspondence: Anthropology in Real Time. In: Design Anthropology: Theorie and Practice. Ed: Gunn, Wendy; Otto, Ton; Smith, Rachel. p. 175-198. Bloosmbury, 2013.

GUNN, Wendy; OTTO, Ton; SMITH, Rachel Charlotte (Ed.). Design anthropology: theory and practice. A\&C Black, 2013.

HARVEY, David. Cidades rebeldes: do direito à cidade à revolução urbana. São Paulo: Martins Fontes, 2014.

INGOLD, Tim. Making: Anthropology, Archaeology, Art and Architecture. Abingdon: Routledge, 2013.

INGOLD, Tim. Estar vivo: ensaios sobre movimento, conhecimento e descrição. Editora Vozes Limitada, 2015.

INGOLD, Tim. Chega de etnografia! A educação da atenção como propósito da antropologia. Revista Educação. Porto Alegre, v. 39, n. 3, p. 404-411, set.-dez. 2016.

INGOLD, Tim. Anthropology and/as Education. Routledge, 2017.

JACOBS, Jane. Morte e vida de grandes cidades. Martins Fontes, 2000.

LATOUR, Bruno. From realpolitik to dingpolitik. Making things public: Atmospheres of democracy: 1444, 2005.

LEFEBVRE, Henri. A produção do espaço. Trad. Doralice Barros Pereira e Sérgio Martins (do original: La production de l'espace. 4e éd. Paris: Éditions Anthropos), [1974] 2000.

LEFEBVRE, Henri. $O$ direito à cidade. Centauro Editora, 2008.

MAGNANI, José Guilherme Cantor. De perto e de dentro: notas para uma etnografia urbana. Revista Brasileira de Ciências Sociais 17.49: 11-29, 2002.

MANZINI, Ezio. Design when everybody designs - an introduction to design for social innovation. Cambridge (Massachusetts) and London : MIT Press, 2015. 
STENGERS, Isabelle. Reativar o animismo, in Caderno de leituras n.62. Tradução Jamille Pinheiro Dias. Chão da Feira, [2012] 2017.

TUNSTALL, Elizabeth. Decolonizing design innovation: design anthropology, critical anthropology, and indigenous knowledge. In: Design anthropology: theory and practice, p. 232-250, 2013.

VAINER, Carlos. Pátria, empresa e mercadoria - Notas sobre a estratégia discursiva do Planejamento Estratégico Urbano. In A Cidade do Pensamento Único. Editora Vozes, 2000.

VIVEIROS DE CASTRO, Eduardo. O nativo relativo. Mana 8.1: 113-148, 2002. 